Portland State University

PDXScholar

8-2013

\title{
Landslide Velocity, Thickness, and Rheology from Remote Sensing; La Clapiere Landslide, France
}

\author{
Adam M. Booth \\ Portland State University, boothad@pdx.edu \\ Michael P. Lamb \\ California Institute of Technology \\ Jean-Philippe Avouac \\ California Institute of Technology \\ Christophe Delacourt
}

Follow this and additional works at: https://pdxscholar.library.pdx.edu/geology_fac

Part of the Geology Commons

Let us know how access to this document benefits you.

\section{Citation Details}

Booth, A. M., Lamb, M. P., Avouac, J., \& Delacourt, C. (2013). Landslide velocity, thickness, and rheology from remote sensing; La Clapiere landslide, France. Geophysical Research Letters, 40(16), 4299-4304.

This Article is brought to you for free and open access. It has been accepted for inclusion in Geology Faculty Publications and Presentations by an authorized administrator of PDXScholar. Please contact us if we can make this document more accessible: pdxscholar@pdx.edu. 


\title{
Landslide velocity, thickness, and rheology from remote sensing: La Clapière landslide, France
}

\author{
Adam M. Booth, ${ }^{1}$ Michael P. Lamb, ${ }^{1}$ Jean-Philippe Avouac, ${ }^{1}$ and Christophe Delacourt ${ }^{2}$ \\ Received 10 June 2013; revised 30 July 2013; accepted 3 August 2013.
}

[1] Quantifying the velocity, volume, and rheology of deep, slow-moving landslides is essential for hazard prediction and understanding landscape evolution, but existing field-based methods are difficult or impossible to implement at remote sites. Here we present a novel and widely applicable method for constraining landslide 3-D deformation and thickness by inverting surface change data from repeat stereo imagery. Our analysis of La Clapière, an $\sim 1 \mathrm{~km}^{2}$ bedrock landslide, reveals a concave-up failure surface with considerable roughness over length scales of tens of meters. Calibrating the thickness model with independent, local thickness measurements, we find a maximum thickness of $163 \mathrm{~m}$ and a rheology consistent with distributed deformation of the highly fractured landslide material, rather than sliding of an intact, rigid block. The technique is generally applicable to any mass movements that can be monitored by active or historic remote sensing. Citation: Booth, A. M., M. P. Lamb, J.-P. Avouac, and C. Delacourt (2013), Landslide velocity, thickness, and rheology from remote sensing: La Clapière landslide, France, Geophys. Res. Lett., 40, doi:10.1002/grl.50828.

\section{Introduction}

[2] Slow-moving, deep-seated landslides are the dominant mechanism of hillslope erosion in many mountainous landscapes, transporting large volumes of sediment from small fractions of the landscape at rates that can vary dramatically in time [Kelsey, 1980; Mackey and Roering, 2011]. Accurately estimating their velocities, volumes, and strength or rheological parameters is essential for determining sediment budgets as well as risks to humans. However, these estimates are notoriously difficult to make because both surface and subsurface data are usually limited to point measurements, for example, in boreholes, and to narrow windows of time. Here we circumvent these limitations by capitalizing on high-resolution remote sensing imagery to measure landslide surface deformation in 3-D and develop a new method to invert this surface change data for failure plane geometry, landslide thickness, and rheology.

Additional supporting information may be found in the online version of this article

${ }^{1}$ Division of Geological and Planetary Sciences, California Institute of Technology, Pasadena, California, USA

${ }^{2}$ Domaines Océaniques, UMR 6538, CNRS-IUEM-UBO, Plouzané, France.

Corresponding author: A. M. Booth, Division of Geological and Planetary Sciences, California Institute of Technology, MC 170-25, 1200 E. California Blvd., Pasadena, CA 91125, USA. (bootha@caltech.edu)

(C)2013. American Geophysical Union. All Rights Reserved. 0094-8276/13/10.1002/grl.50828
[3] Previous work has shown that correlation of repeat aerial stereo optical imagery can generate detailed 3-D surface displacement maps for large, slow-moving landslides [e.g., Kääb, 2002; Delacourt et al., 2004]. It is also possible to qualitatively infer landslide failure plane geometry from measurements of surface displacements [e.g., Carter and Bentley, 1985; Bishop, 1999], but previous studies lacked the high-resolution surface change data needed for a complete 3-D reconstruction. Glaciologists have shown that measurements of glacier velocities and apparent thickness changes can be used to accurately predict the position of the glacier's bed using standard techniques from inverse theory [Rasmussen, 1988; Farinotti et al., 2009; Morlighem et al., 2011]. In this study, we develop a similar technique in which we invert the mass conservation equation for landslide thickness using a measured 3-D surface deformation field. The technique requires only surface change data and the simple assumption that the landslide's depth-averaged velocity is a spatially constant fraction of the observed surface velocity. Calibrating the resulting failure plane model to match one or more local, direct thickness measurement constrains both landslide rheology and the thickness at all other locations within the landslide. We apply the technique to La Clapière landslide, southeastern France, an $\sim 1 \mathrm{~km}^{2}$ bedrock landslide moving at rates averaging several meters per year, and use the resulting thickness model to determine the landslide's volume, rock strength, rheology, and controls on its slip surface geometry.

\section{Thickness Inversion}

[4] For a landslide of constant density, conservation of mass implies that

$$
\frac{\partial h}{\partial t}=-\nabla \cdot(\overline{\boldsymbol{u}} h)
$$

where $h$ is landslide thickness (with units of length, L), $t$ is time (T), and $\overline{\boldsymbol{u}}$ is the depth-averaged horizontal landslide velocity vector $\left(\mathrm{L} \mathrm{T}^{-1}\right)$. Since we can measure surface velocity remotely, we make a simplifying assumption, valid for landslides that are thin relative to their length, that $\overline{\boldsymbol{u}}=f \boldsymbol{u}_{\text {surf }}$, where $\boldsymbol{u}_{\text {surf }}$ is the surface horizontal velocity vector $\left(\mathrm{L} \mathrm{T}^{-1}\right)$ and $f$ is a constant between 0 and 1 that depends on landslide rheology. Although landslides might have heterogeneous material properties, this is rarely quantified, and defining $f$ as constant implies that the landslide's rheology is spatially uniform so that changes in thickness alone are responsible for the observed 3-D deformation field. In the general case of a power law landslide rheology and slender flow approximation, where shear strain rate is proportional to shear stress raised to an exponent [Booth et al., 2013], $f=1 / 2$ is consistent with a linear vertical velocity profile, $f=2 / 3$ with Newtonian viscous flow, $2 / 3<f<1$ with plug flow, and $f=1$ with a rigid sliding block. Assuming that the 


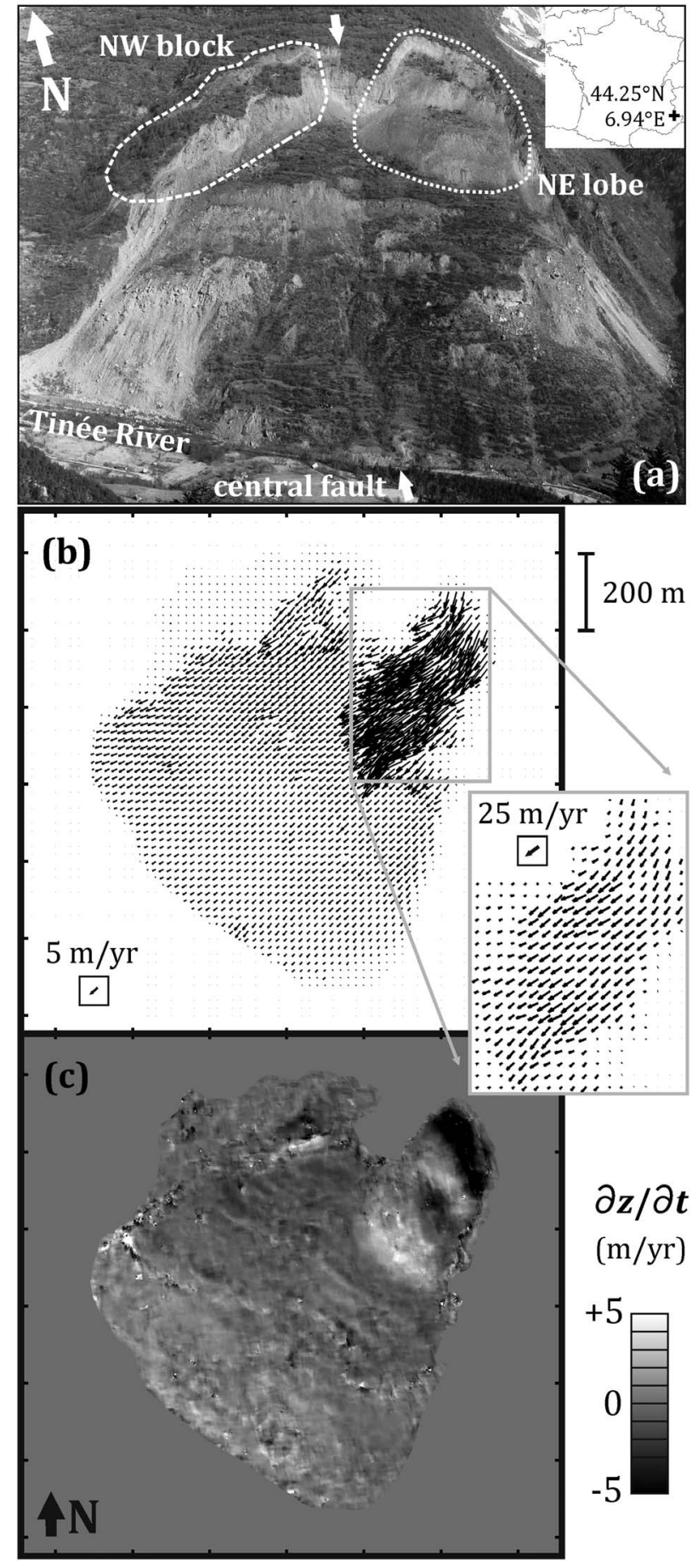

Figure 1. (a) Photo of La Clapière landslide (from the Gravitational Landslide Observatory by Geoazur, http:// gravitaire.oca.eu/) taken in 1997, midway through the time interval analyzed in this study. Paired white arrows indicate the central fault, which separates the main body of the landslide into two independently deforming masses. Dashed outlines indicate two morphologic subunits of the landslide referred to in the main text. (b) The average horizontal surface velocity field and (c) vertical change in elevation field averaged over the time interval 1995-1999 (section 3). elevation of the landslide's basal surface does not change over a short interval of time, equation (1) simplifies to

$$
\frac{\partial z}{\partial t}=-\nabla \cdot\left(f \boldsymbol{u}_{\text {surf }} h\right)
$$

where $z$ is the land surface elevation (L). Generally, $\partial z / \partial t$ can be measured by differencing digital elevation models (DEMs) [e.g., Schwab et al., 2008; DeLong et al., 2012], while $\boldsymbol{u}_{\text {surf }}$ can be measured by correlating orthorectified imagery [e. g., Delacourt et al., 2007; Debella-Gilo and Kääb, 2012].

[5] Equation (2) can be approximated on a finite difference grid and written as a system of $N$ linear equations of the form $A h_{f}=b$, where $N$ is the number of pixels in the velocity and elevation change grids, $A$ is a diagonally dominant matrix containing the surface velocity data, $h_{f}=f h$ is a vector of the unknown thicknesses, scaled by $f$, and $b$ is a vector containing the change in elevation data (supporting information). Here we associate the constant $f$ with thickness, rather than surface velocity, to highlight the effects of the assumed rheology on the predicted thickness model, or conversely, the effect of a known thickness on the inferred rheology. In the former case, different values of $f$ correspond to different thickness models, each with the same spatial pattern, but with a magnitude that scales as $f^{-1}$. In the latter, at least one independently measured thickness can constrain rheology by determining the value of $f$ that results in the best match between the measured and predicted thicknesses.

[6] This inverse problem can be ill posed and therefore generally requires regularization to give stable, meaningful results. We determine the preferred thickness model using second-order Tikhonov regularization by minimizing the expression

$$
\left\|A h_{f}-b\right\|^{2}+\alpha^{2}\left\|\nabla^{2} h_{f}\right\|^{2}
$$

where the double brackets indicate the Euclidian norm, and $\alpha$ is a damping factor that assigns a weight to minimizing the thickness model's Laplacian such that a higher $\alpha$ results in a smoother model. To select an appropriate $\alpha$, we apply the discrepancy principle, which amounts to determining the smoothest model that fits the observations within their uncertainties (supporting information). We use CVX, a program to solve convex optimization problems [CVX Research, Inc., 2013], to find $h_{f}$ that minimizes expression (3) subject to the constraints that $h \geq 0$ everywhere and that $h \approx 0$ on stable terrain.

\section{Study Area: La Clapière Landslide}

[7] La Clapière landslide is an $\sim 1 \mathrm{~km}^{2}$ bedrock landslide located just south of Saint-Etienne-de-Tinée, France (Figure 1a). We focus on this site because it has been the subject of numerous geotechnical studies, several of which estimated its thickness at a few point locations. The underlying bedrock is mainly migmatitic gneiss with foliation that dips moderately to the NE into the affected hillslope, and a subhorizontal band of metadiorite (Iglière bar) crosses the landslide at an elevation of $\sim 1350 \mathrm{~m}$ [Follacci, 1987]. The landslide moves mainly to the SW, cutting across the foliation and metadiorite bar. The rocks are pervasively weathered, fractured, and faulted, and a major fault striking NNE cuts through the main landslide mass (Figure 1a). A faster-moving subsidiary landslide, which we call the NE lobe, overrides the upper eastern part of the main landslide, while a displaced block of material, the NW block, sits high along the landslide's western margin. 
Table 1. Validation of Inversion-Predicted Landslide Thicknesses

\begin{tabular}{|c|c|c|c|}
\hline Reference & Reference Location & Reported Thickness (m) & This Study, Thickness (m) \\
\hline \multirow[t]{3}{*}{ Gaffet et al. $[2010]^{\mathrm{a}}$} & Station $29 \mathrm{~A}$ & $44 \pm 8$ & $38 \pm 10$ \\
\hline & Station $29 \mathrm{C}$ & $78 \pm 14$ & $38 \pm 13$ \\
\hline & Station 29D & $\approx 66^{\mathrm{b}}$ & $80 \pm 17$ \\
\hline \multirow[t]{2}{*}{ Jomard et al. $[2007]^{\mathrm{c}}$} & Profile 1 & $<30-40$ & $\approx 10-30$ \\
\hline & Profile 2 & $<20-30$ and $\approx 90$ & $\approx 0$ \\
\hline Cappa et al. [2004], Guglielmi et al. [2004, 2005], Chemenda et al. [2009] & Main landslide & $<100-200$ & $<163 \pm 19$ \\
\hline
\end{tabular}

\footnotetext{
${ }^{\text {a}}$ Stations 29A, 29C, and 29D located on the upper part of the main landslide (Figure 2).

${ }^{\mathrm{b}}$ Approximate thickness due to limited data, uncertainty not reported.

${ }^{\mathrm{c}}$ Profile 1 traverses the lower part of the NE lobe, and Profile 2 traverses just below the NE lobe.
}

[8] The surrounding hillslope contains numerous large extensional deformation features that initiated with the retreat of a valley glacier $\sim 13 \mathrm{ka}$ and slowly deformed the slope until triggering the landslide near the toe of the slope in the 1930s [Guglielmi and Cappa, 2010]. The landslide grew to approximately its current areal extent by the 1950s [Guglielmi et al., 2004] and has since had surface velocities that varied considerably spatially, but averaged several meters per year. We determine the surface velocity and change in elevation fields for the time period 1995 to 1999 using $1 \mathrm{~m}$ resolution digitized stereo aerial photography (Figures $1 \mathrm{~b}$ and $1 \mathrm{c}$ ). The change in elevation field is the difference between the DEMs constructed from each stereo pair [Casson et al., 2005] after aligning the 1995 DEM to the 1999 DEM. We estimate the horizontal surface velocity field by correlating the corresponding orthorectified images [Delacourt et al., 2004], manually tracking several bushes in the NE lobe where coherence between images is poor, and removing all spurious displacements due to false correlations near the boundary of the NE lobe.

[9] Previous work has approximated the overall maximum thickness of La Clapière and determined its thickness at a few point locations, but no studies have quantitatively predicted
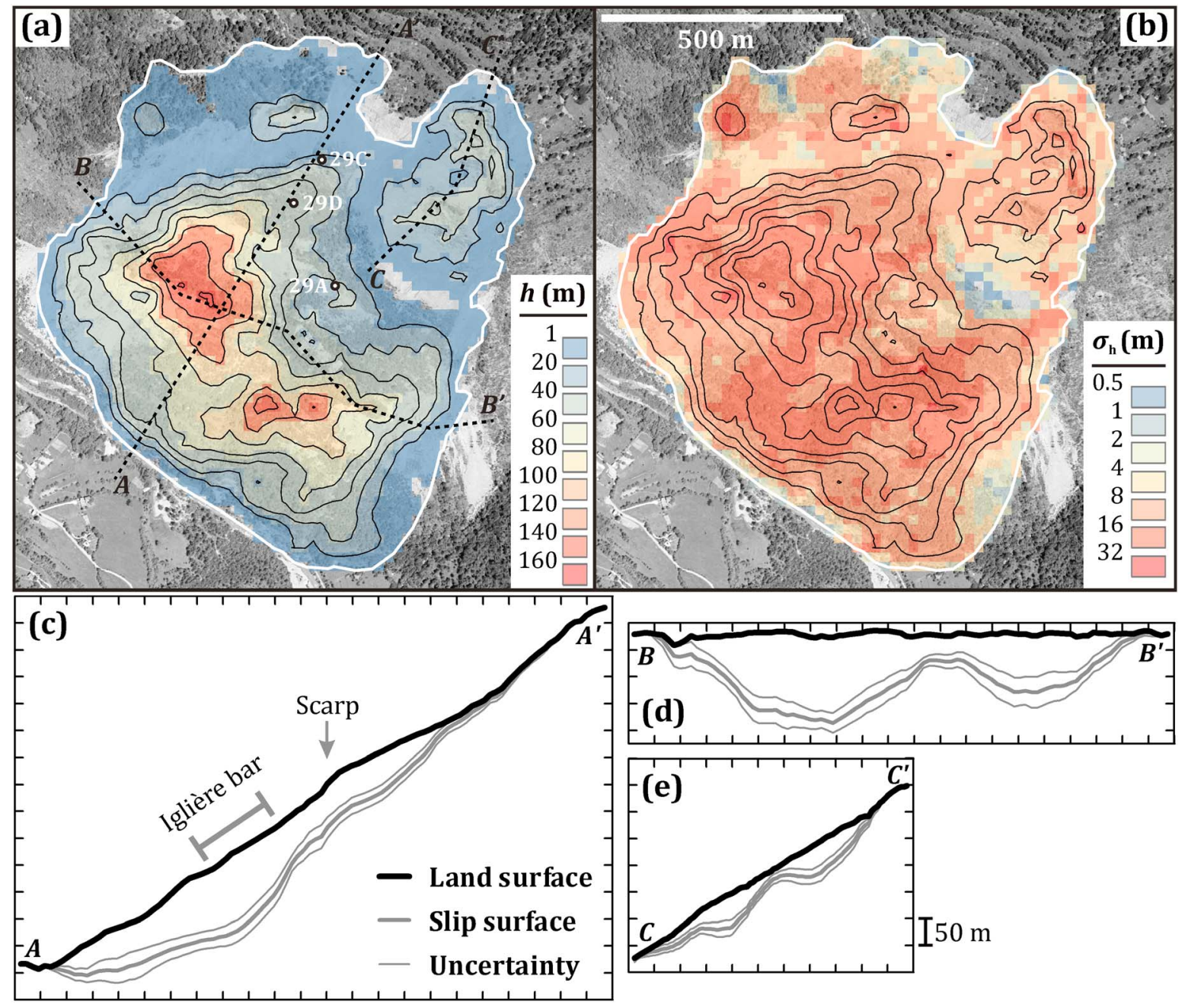

Figure 2. (a) Predicted landslide thickness, $h$, and (b) its uncertainty, $\sigma_{h}$, with thickness contours overlain. In Figure $2 \mathrm{a}$, points labeled 29A, 29C, and 29D refer to locations from Gaffet et al. [2010] (Table 1). (c, d) Profiles $A A^{\prime}, B B^{\prime}$, and $C C^{\prime}$ are shown with no vertical exaggeration and $50 \mathrm{~m}$ tick marks on the axes. 


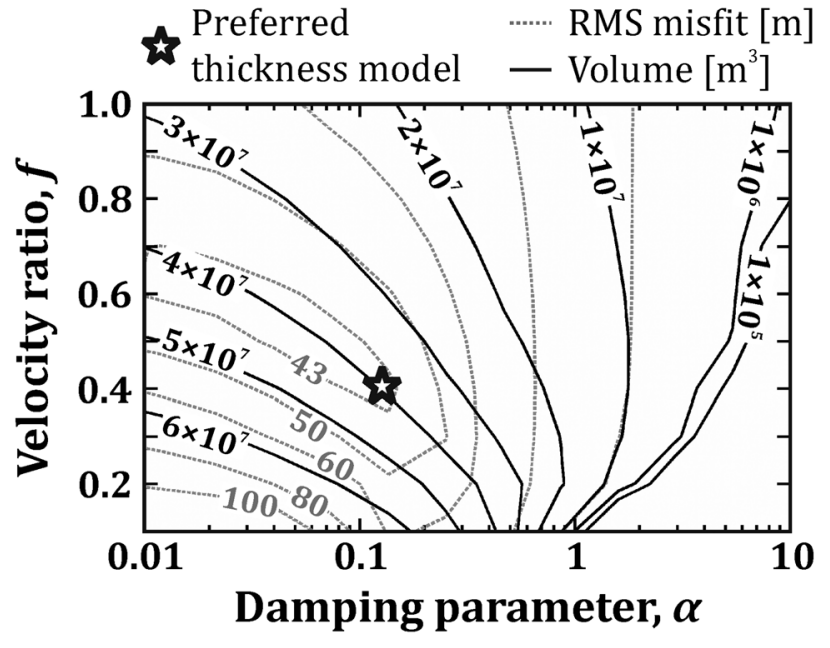

Figure 3. Contours of predicted landslide volume (solid black lines) and route mean square misfit between modeled thickness and observed thickness in Gaffet et al. [2010] (dashed gray lines) as a function of the damping parameter, $\alpha$, and the velocity ratio, $f$. The star indicates the location of the optimal thickness model, with $\alpha$ given by the discrepancy principle (section 2 ) and $f$ chosen to minimize the RMS misfit (Table 1).

its entire 3-D subsurface geometry. Cross-sectional geometry [Cappa et al., 2004; Guglielmi et al., 2005] and finite element simulations [Guglielmi et al., 2004; Chemenda et al., 2009] suggest that the landslide is a maximum of 100 to $200 \mathrm{~m}$ thick (Table 1). The 3-D displacement field qualitatively suggests a concave-up slip surface [Casson et al., 2005], while geotechnical investigations indicate that the central fault accommodates differential movement [Follacci, 1987]. On the lowermost part of the NE lobe, electrical resistivity measurements indicate a bowl-shaped slip surface 20-40 m deep, as well as a deeper potential failure plane at $90 \mathrm{~m}$ [Jomard et al., 2007]. We use all the above inferences and measurements to evaluate the performance of our thickness inversion (section 4).

[10] Additionally, resonant frequency analysis of background seismicity at three stations spaced hundreds of meters apart on the upper part of the main landslide body suggests local thicknesses of 44, 66, and $78 \mathrm{~m}$ [Gaffet et al., 2010] (Table 1). Since these measurements are from specific locations and have rigorously defined uncertainties, we use them to determine La Clapière's optimal thickness model and constrain its rheology by selecting $f$ that minimizes the misfit between the inversion-predicted and measured thicknesses at those locations (section 4).

\section{Results}

[11] Our optimal thickness model (Figure 2) predicts that La Clapière has a generally concave-up slip surface with a maximum depth of $163 \pm 19 \mathrm{~m}$ (mean \pm 1 standard deviation), in agreement with previous estimates of 100-200 m [Cappa et al., 2004; Guglielmi et al., 2004, 2005; Chemenda et al., 2009]. This thickness model assumes that $\alpha=0.16$, which satisfies the discrepancy principle (section 2 and supporting information), and $f=0.4$, which minimizes the root-mean-square (RMS) misfit between our thickness model and the measured thicknesses of Gaffet et al. [2010] at stations 29A, 29C, and $29 \mathrm{D}$ (Figure 2a and Table 1). Figure 3 illustrates the effect of a change in either of these parameters on the misfit as well as on the inferred landslide volume. So long as $\alpha$ is less than about unity, it does not strongly affect the estimated volume because it primarily controls the smoothness of the thickness model and not the average thickness (supporting information). The volume is quite sensitive to $f$ because this constant directly scales the magnitudes of the predicted thicknesses (section 2). The uncertainty of the landslide thickness, $\sigma_{h}$, estimated with a bootstrapping approach (supporting information) averages $13 \mathrm{~m}$ over the extent of the landslide, but scales with $h$ as $\sigma_{h}=(0.188 \pm 0.004)$ $h+(1.86 \pm 0.14)$, reported with $95 \%$ confidence bounds.

[12] The thickness model reveals four main landslide sections with distinct failure plane geometries. The central fault divides the main body of the landslide into two large sections (Figure $2 \mathrm{~d}$ ), each with a concave-up slip surface. To the west of the central fault, the slip surface of the largest section extends continuously from the exposed head scarp to the landslide toe where it infringes on the Tinée River (Figure 2c), while the eastern section extends from below the NE lobe of the landslide to the toe and is thinner. The fast-moving NE lobe, with velocities up to $25 \mathrm{~m} \mathrm{yr}^{-1}$, is up to $68 \pm 16 \mathrm{~m}$ thick, and the slip surface there forms two main depressions (Figure 2e). On its toe, calculated thickness decreases in the downslope direction from the maximum to zero and is similar to that inferred from electrical resistivity measurements [Jomard et al., 2007]. The NW block contains a small zone with a maximum thickness of $62 \pm 21 \mathrm{~m}$, which corresponds to a smaller subsidiary block that moved $\sim 25 \mathrm{~m}$ from 1995 to 1999. The remaining portion of the NW block did not move significantly during the time interval studied, and the inversion shows thicknesses near zero there.

[13] We constrain the volume of the entire active part of La Clapière from 1995 to 1999 to be $3.81 \pm 0.03 \times 10^{7} \mathrm{~m}^{3}$. Given its area of $8.1 \times 10^{5} \mathrm{~m}^{2}$, this estimate is in agreement with that predicted by global landslide volume-area scaling relationships [Guzzetti et al., 2009; Larsen et al., 2010], but is only $\sim 64$ to $76 \%$ of the previous volume estimates for this landslide [Guglielmi et al., 2005; Jomard et al., 2007; Gaffet et al., 2010]. The discrepancy partly results from the exclusion of the NW block in this study, and from the detailed geometry of the failure plane revealed by our inverse technique compared to previous studies.

[14] Detailed knowledge of landslide thickness allows us to estimate frictional strength of the failure plane from classical Coulomb friction. To do so, we follow the conventional method of slices approach for slope stability analysis [Fellenius, 1936; Selby, 1993, p. 268], which treats the landslide as an ensemble of vertical columns in order to calculate stresses at the landslide's base. We treat each column of rock in the $20 \mathrm{~m}$ grid independently and resolve its weight into the normal stress component as $W \cos \theta / A$, where $W$ is weight [ $\mathrm{M} \mathrm{L} \mathrm{T}^{-2}$ ], $\theta$ is dip angle, and $A$ is the surface area of the column base $\left[\mathrm{L}^{2}\right]$, and the shear stress component as $W \sin \theta_{u} / A$, where $\theta_{u}$ is the dip in the direction of movement. Assuming no cohesion and no pore water pressure, the ratio of shear stress to normal stress at the base of each column gives its dry coefficient of friction, $\mu=\tan \phi$, where $\phi$ is the friction angle. With this technique and assuming a bulk density of $2700 \mathrm{~kg} \mathrm{~m}^{-3}$, $\phi=32^{\circ} \pm 1^{\circ}($ mean $\pm 95 \%$ confidence interval) averaged over all columns. Additionally, a landslide's factor of safety is the total Coulomb strength of a potential failure surface divided 
by the total shear stress on that surface. Assuming a factor of safety of unity, this technique gives a friction angle of $\phi=29^{\circ}$. Both these estimates agree with laboratory strength measurements of fault gouge material at the edge of the landslide where $\phi$ ranges from $28^{\circ}$ to $33^{\circ}$, and cohesion is less than $3 \mathrm{kPa}$ [Lebourg et al., 2011], suggesting that the landslidescale strength is similar to the laboratory-scale strength of the weakest material tested at the site under dry conditions.

\section{Discussion and Conclusions}

[15] A particularly interesting result of our landslide thickness inversion is that at La Clapière, the depth-averaged velocity must be much lower than the surface velocity $(f=0.4)$ in order for the inversion-predicted thicknesses to match independent local thickness measurements from shallow geophysical techniques. In other words, the landslide is not well approximated as a rigid sliding block $(f=1)$, and instead is better approximated by granular flow in a pile $(f<0.5[\mathrm{MiDi}, 2004])$ or a combination of forward toppling and basal sliding, both of which indicate shear deformation within the sliding mass. The small value of $f$ might be due to the landslide's orientation in the Tinée valley where its movement cuts across planes of weakness associated with foliation and exploits a discontinuous network of fractures, faults, and weathered rock throughout its thickness [Cappa et al., 2004].

[16] A second noteworthy result is that the thickness of the landslide must vary considerably over length scales of tens of meters in order to accurately reproduce the change in elevation field at those length scales. This apparent roughness of the base of the landslide suggests lithological and structural controls on the basal geometry. For example, a profile down the western part of the landslide shows that the basal surface steepens where it cuts the Iglière bar, just below a small scarp paralleling the slip surface (Figure 2c). These features document a lithologic control on the landslide's geometry such that the bar divides the landslide into an upper part with a failure plane that developed as the landslide initiated in the 1930s, and a lower part that did not develop a failure plane until the 1980s as the landslide propagated to the foot of the hillslope [Follacci, 1987].

[17] The method presented here for estimating landslide thickness is general and applicable to a large number and types of landslides where surface change data can be collected and rheology can be assumed or is known. The predicted thicknesses, and therefore landslide volume, scale with $f^{-1}$ for a given $\alpha$ (equation (S2)), but the spatial pattern of the thickness model is not sensitive to $f$. This means that even if rheology is poorly known for a given landslide, our technique can still reveal the overall geometry and variability of its basal surface if rheology is assumed spatially constant. If even a single direct measurement of local thickness can be made, for example, in a borehole or with shallow geophysical techniques, that measurement can constrain rheology and thickness throughout the entire landslide by determining $f$ that minimizes the misfit between the observed and inversion-predicted thicknesses (section 4). Additional measurements of a landslide's vertical velocity profile, which can be measured with borehole inclinometers, could further constrain $f$ and how it might vary spatially.

[18] We suggest that this inverse technique can improve traditional analyses of accessible and well-instrumented sites, such as La Clapière, by extending point observations of thickness to an entire 3-D reconstruction of a landslide's subsurface. The ability of airborne or spaceborne imagery to provide data remotely also opens up a wide range of inaccessible landslides to study and extends the observational period to historical time scales, enabling future work to tie 3-D landslide kinematics to changes in land use, tectonics, and climate.

[19] Acknowledgments. We thank S. Gaffet for the coordinates of seismic stations, S. Leprince for fruitful discussions, and Y. Guglielmi and G. Hilley for insightful reviews. This work was supported by the Keck Institute for Space Studies and Terrestrial Hazard Observation and Reporting Center at Caltech.

[20] The Editor thanks George Hilley and an anonymous reviewer for assistance evaluating this paper.

\section{References}

Bishop, K. M. (1999), Determination of translational landslide slip surface depth using balanced cross sections, Environ. Eng. Geosci., 2, 147-156.

Booth, A. M., J. J. Roering, and A. W. Rempel (2013), Topographic signatures and a general transport law for deep-seated landslides in a landscape evolution model, J. Geophys. Res. Earth Surf., 118, 603-624, doi:10.1002/jgrf.20051

Cappa, F., Y. Guglielmi, V. M. Soukatchoff, J. Mudry, C. Bertrand, and A. Charmoille (2004), Hydromechanical modeling of a large moving rock slope inferred from slope levelling coupled to spring long-term hydrochemical monitoring: Example of the La Clapière landslide (Southern Alps, France), J. Hydrol., 291(1-2), 67-90, doi:10.1016/j. jhydrol.2003.12.013.

Carter, M., and S. P. Bentley (1985), The geometry of slip surfaces beneath landslides: Predictions from surface measurements, Can. Geotech. J., 22, 234-238.

Casson, B., C. Delacourt, and P. Allemand (2005), Contribution of multitemporal remote sensing images to characterize landslide slip surfaceApplication to the "La Clapière" landslide (France), Nat. Haz. Earth Sys. Sc., 5, 425-437.

Chemenda, A. I., T. Bois, S. Bouissou, and E. Tric (2009), Numerical modelling of the gravity-induced destabilization of a slope: The example of the La Clapière landslide, southern France, Geomorphology, 109(3-4), 86-93, doi:10.1016/j.geomorph.2009.02.025.

CVX Research, Inc. (2013), CVX: Matlab software for disciplined convex programming, version 2.0 beta., edited.

Debella-Gilo, M., and A. Kääb (2012), Measurement of surface displacement and deformation of mass movements using least squares matching of repeat high resolution satellite and aerial images, Remote Sens., 4(12), 43-67, doi:10.3390/rs4010043.

Delacourt, C., P. Allemand, B. Casson, and H. Vadon (2004), Velocity field of the "La Clapière" landslide measured by the correlation of aerial and QuickBird satellite images, Geophys. Res. Lett., 31, L15619, doi:10.1029/2004gl020193.

Delacourt, C., P. Allemand, E. Berthier, D. Raucoules, B. Casson, P. Grandjean, C. Pambrun, and E. Varel (2007), Remote-sensing techniques for analysing landslide kinematics: A review, Bull. Soc. Geol. Fr., 178(2), 89-100, doi:10.2113/gssgfbull.178.2.89.

DeLong, S. B., C. S. Prentice, G. E. Hilley, and Y. Ebert (2012), Multitemporal ALSM change detection, sediment delivery, and process mapping at an active earthflow, Earth Surf. Processes Landforms, 37(3), 262-272, doi:10.1002/esp.2234.

Farinotti, D., M. Huss, A. Bauder, M. Funk, and M. Truffer (2009), A method to estimate the ice volume and ice-thickness distribution of alpine glaciers, J. Glaciol., 55(191), 422-430.

Fellenius, W. (1936), Calculation of the stability of earth dams, Transactions, 2nd Congress on Large Dams (Washington, CD), 4, 445-465.

Follacci, J. P. (1987), Les mouvements de versant de La Clapière à SaintEtienne de Tinée (Alpes Maritimes), Bull. Liaison Lab. Ponts Chausseés, 150(151), 39-54.

Gaffet, S., Y. Guglielmi, F. Cappa, C. Pambrun, T. Monfret, and D. Amitrano (2010), Use of the simultaneous seismic, GPS and meteorological monitoring for the characterization of a large unstable mountain slope in the southern French Alps, Geophys. J. Int., 182(3), 1395-1410, doi:10.1111/j.1365-246X.2010.04683.x.

Guglielmi, Y., and F. Cappa (2010), Regional-scale relief evolution and large landslides: Insights from geomechanical analyses in the Tinée Valley (southern French Alps), Geomorphology, 117(1-2), 121-129, doi:10.1016/j.geomorph.2009.11.016. 


\section{BOOTH ET AL.: LANDSLIDE THICKNESS FROM REMOTE SENSING}

Guglielmi, Y., F. Cappa, S. Binet, F. Bigot-Cormier, and E. Tric (2004), Multi-scale rock slope failure initiation mechanisms: results from multiparametric field and modeling studies conducted on the Upper Tinée valley (French Alps) over the past 10 years, paper presented at GeoHazards 2004 Workshop, Shizuoka, Japan.

Guglielmi, Y., F. Cappa, and S. Binet (2005), Coupling between hydrogeology and deformation of mountainous rock slopes: Insights from La Clapière area (southern Alps, France), C. R. Geosci., 337(13), 1154-1163, doi:10.1016/j.crte.2005.04.016

Guzzetti, F., F. Ardizzone, M. Cardinali, M. Rossi, and D. Valigi (2009), Landslide volumes and landslide mobilization rates in Umbria, central Italy, Earth Planet. Sci. Lett., 279(3-4), 222-229, doi:10.1016/j. eps1.2009.01.005.

Jomard, H., T. Lebourg, and E. Tric (2007), Identification of the gravitational boundary in weathered gneiss by geophysical survey: La Clapière landslide (France), J. Appl. Geophys., 62(1), 47-57, doi:10.1016/j. jappgeo.2006.07.003

Kääb, A. (2002), Monitoring high-mountain terrain deformation from repeated air- and spaceborne optical data: examples using digital aerial imagery and ASTER data, ISPRS J. Photogramm. Remote Sens., 57, 39-52.

Kelsey, H. (1980), A sediment budget and an analysis of geomorphic process in the Van Duzen River basin, north coastal California, 1941-1975, Geol. Soc. Am. Bull., 91, 1119-1216.

Larsen, I. J., D. R. Montgomery, and O. Korup (2010), Landslide erosion controlled by hillslope material, Nat. Geosci., 3(4), 247-251, doi:10.1038/ Ngeo776.
Lebourg, T., H. Mickael, J. Hervé, E. B. B. Samyr, B. Thomas, Z. Swann T. Emmanuel, and V. Maurin (2011), Temporal evolution of weathered cataclastic material in gravitational faults of the La Clapiere deep-seated landslide by mechanical approach, Landslides, 8(2), 241-252, doi:10.1007/s10346-010-0244-6.

Mackey, B. H., and J. J. Roering (2011), Sediment yield, spatial characteristics, and the long-term evolution of active earthflows determined from airborne LiDAR and historical aerial photographs, Eel River, California, Geol. Soc. Am. Bull., 123(7-8), 1560-1576, doi:10.1130/ b30306.1.

MiDi, G. D. R. (2004), On dense granular flows, Eur. Phys. J.. E, Soft Matter, 14(4), 341-365, doi:10.1140/epje/i2003-10153-0.

Morlighem, M., E. Rignot, H. Seroussi, E. Larour, H. Ben Dhia, and D. Aubry (2011), A mass conservation approach for mapping glacier ice thickness, Geophys. Res. Lett., 38, L19503, doi:10.1029/ 2011 g1048659.

Rasmussen, L. A. (1988), Bed topography and mass-balance distribution of Columbia glacier, Alaska, U.S.A., determined from sequential aerial photography, J. Glaciol., 34(117), 208-216.

Schwab, M., D. Rieke-Zapp, H. Schneider, M. Liniger, and F. Schlunegger (2008), Landsliding and sediment flux in the Central Swiss Alps: A photogrammetric study of the Schimbrig landslide, Entlebuch, Geomorphology, 97(3-4), 392-406, doi:10.1016/j. geomorph.2007.08.019.

Selby, M. J. (1993), Hillslope Materials and Processes, 2nd ed., Oxford University Press, Oxford 